\title{
Long-Term (1-Year) Safety and Efficacy of a Single 6-mL Injection of Hylan G-F 20 in Indian Patients with Symptomatic Knee Osteoarthritis
}

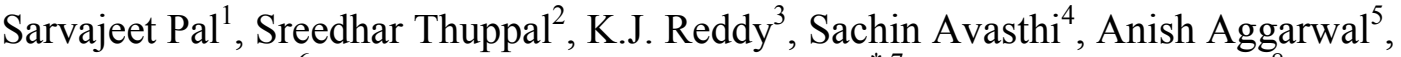 \\ Himanshu Bansal ${ }^{6}$, Senthilnathan Mohanasundaram ${ }^{*, 7}$ and Francois Bailleul ${ }^{8}$ \\ ${ }^{I}$ Advance Rheumatology Clinic, Andhra Pradesh, India \\ ${ }^{2}$ Kamineni Hospitals, Andhra Pradesh, India \\ ${ }^{3}$ Apollo Hospitals, Andhra Pradesh, India \\ ${ }^{4}$ Department of Orthopaedics, GSVM Medical College and Associated Hospital, Uttar Pradesh, India \\ ${ }^{5}$ Brij Medical Centre, Uttar Pradesh, India \\ ${ }^{6}$ Genzyme India Pvt. Ltd., Haryana, India \\ ${ }^{7}$ Sanofi-Synthelabo (India) Ltd., Mumbai, India \\ ${ }^{8}$ Genzyme Biosurgery (Formerly), Saint Germain en Laye Cedex, France
}

\begin{abstract}
Introduction: The prevalence of symptomatic knee osteoarthritis (OA) among Asians $\geq 65$ years is estimated to double by 2040 . This study was designed to evaluate the safety and efficacy of a single, 6-mL intra-articular injection of hylan G-F 20 in Indian patients with knee OA at 26 weeks through to 52 weeks.

Methods: This study was an open-label, multicentre, phase 4 clinical trial. Enrolled patients $(\mathrm{N}=394)$ were $\geq 30$ years old with Kellgren-Lawrence grade 1-3 OA; all patients received hylan G-F 20. WOMAC, SF-12, PTGA, and COGA scores, and OA medication use were evaluated at weeks 1, 4, 12, 26, 39, and 52 (initial treatment phase). At 26, 39, or 52 weeks, eligible patients could participate in a repeat treatment phase. McNemar-Bowkers, paired t-tests and ANOVA analyses were performed (alpha $=0.05$ ).

Results: At 26 weeks, statistically significant changes from baseline were observed in all efficacy parameters, including the primary efficacy endpoint of WOMAC A1 $(\mathrm{p}<0.0001)$. Improvements continued for 52 weeks. No significant changes occurred in concomitant medication use. Eleven patients $(2.8 \%)$ were re-injected at week 26 or 52 . After repeat injection, statistically significant decreases were observed in WOMAC A1, WOMAC C and PTGA scores $(\mathrm{p} \leq 0.028)$. Twenty-three (5.8\%) patients reported 26 local target knee AEs.

Conclusion: Among Indian patients within this study, a 6-mL hylan G-F 20 injection was well tolerated and effective in treating symptomatic knee OA with significant long-term (1 year) improvement of outcomes. When needed, repeat treatment was safe and efficacious for 4 weeks.
\end{abstract}

Trial Registration: Clinical Trial Registry of India (CTRI/2010/091/000052) www.ctri.nic.in/Clinicaltrials/login.php.

Keywords: Hyaluronan, hylan G-F 20, osteoarthritis, Western Ontario and McMaster Universities Osteoarthritis Index.

\section{INTRODUCTION}

Osteoarthritis (OA) is a common joint disease, frequently causing physical impairment [1]. The prevalence of symptomatic knee OA increases with age, with the percentage of Asians $\geq 65$ years estimated to double by 2040 [2]. Likewise, obesity is a known risk factor, and obesity is rising in many Asian countries, including India [2, 3].

OA of the knee is characterised by several pathophysiological changes, including decreased concentration and quality

*Address correspondence to this author at the Sanofi-Synthelabo (India) Limited, 54/A, Sir Mathuradas Vasanji Road, Andheri (E), Mumbai 400093, India; Tel: +91 (0) 222827 8059; Fax: +91 (0) 222827 8052;

E-mail: senthilnathan.mohanasundaram@sanofi.com of hyaluronan in synovial fluid [4, 5]. Viscosupplementation with hyaluronic acid (HA) helps to alleviate pain by supplementing the osteoarthritic synovial fluid, restoring physiological and rheological states of arthritic joints [5].

Hylan G-F 20, a high molecular weight, crosslinked derivative of $\mathrm{HA}$, has been demonstrated to be safe and effective for the treatment of OA pain of the knee in patients who have failed to respond adequately to conservative nonpharmacologic therapy and simple analgesics [6-12]. Several large, randomised clinical studies have shown efficacy with 3 weekly intra-articular (IA) injections of hylan G-F 20 for the treatment of knee OA [6-8, 11, 12]. Also, a single injection of 6-mL hylan G-F 20 (Synvisc-One ${ }^{\circledR}$, Genzyme Biosurgery, Ridgefield, NJ, United States) has 
shown efficacy in alleviating knee OA pain over 26 weeks without safety concerns [9]. It has been approved for the treatment of knee OA pain in India since 2010 [13].

The objective of this study was to evaluate the safety and efficacy of hylan G-F 20 in patients with symptomatic knee $\mathrm{OA}$ in India over 26 weeks using Western Ontario and McMaster Universities Osteoarthritis Index (WOMAC) A1 scale (walking pain). Secondary efficacy endpoints were to evaluate the WOMAC A, B, and C subscores; the patient global assessment (PTGA), the clinical observer global assessment (COGA), and short form-12 (SF-12) scores over 26 weeks and up to 52 weeks; and to assess the short-term efficacy and safety of a repeat treatment with hylan G-F 20 (if needed) after week 26 with a duration of 4 weeks of follow-up.

\section{MATERIALS AND METHODOLOGY}

\section{Patient Population}

Patients were $\geq 30$ years of age with a diagnosis of Kellgren-Lawrence grades 1-3 OA of the target knee confirmed by an X-ray. Grade 1-3 OA patients were included as they have mild to moderate OA; grade $4 \mathrm{OA}$ patients have severe OA and are eligible for a total knee replacement. Baseline scores for the WOMAC A1 visual analogue scale (VAS) scores had to be between 40 and 80 $\mathrm{mm}$ (moderate to severe walking pain) in the target knee. In bilateral treatments, the worst knee (by WOMAC A1 score) was considered the target knee.

Exclusion criteria were significant (requiring surgical correction) valgus or varus deformity of the knee, ligamentous laxity, or meniscal instability; concomitant inflammatory or any other disease/condition which might affect joints; positive urine pregnancy test; any history of sepsis in any joint or any clinical concern for a subacute infectious process or surgery in the target joint; clinically significant venous or lymphatic stasis present in the leg(s) or clinically apparent tense effusion or inflammation at the target knee; hypersensitivities to any components of HAbased injection; and treatment with any HA or its derivatives in the previous 6 months or IA steroid in the previous 3 months.

\section{Study Design}

OASIS (Osteoarthritis Synvisc-One ${ }^{\circledR}$ Indian PostMarketing Study) was an open-label, multicentre, phase 4 clinical study to evaluate the safety and efficacy of a single 6-mL injection of hylan G-F 20 in Indian patients with symptomatic OA of the knee(s). Eligible patients were enrolled in the study. If the patient did not have a valid knee $\mathrm{X}$-ray taken within 3 months prior to the baseline visit, then an anterioposterior X-ray with a lateral or skyline view was obtained at baseline.

The study consisted of an initial treatment phase with one intra-articular injection of hylan G-F 20, and a repeat treatment phase, if needed. During both treatment phases, the safety and efficacy of hylan G-F 20 was assessed.

The initial treatment phase consisted of 52 weeks divided into 7 visits where visit 1 was the screening/baseline visit and the remaining 6 were the subsequent follow-up visits to the clinic (at weeks 1, 4, 12, 26, 39, and 52). At the first visit, arthrocentesis was performed in the knee(s) to be treated with removal of synovial fluid followed by a single, 6-mL hylan G-F 20 injection. Patients were then asked to rest the injected joint for 24 hours.

At weeks 26, 39, and 52, patients could participate in a 4week, open-label repeat treatment phase, if medically warranted. Repeat eligibility criteria were the same as those for study entry plus no major safety concerns during the first course of treatment. Patients meeting the repeat treatment eligibility criteria received a second injection of hylan G-F 20 on repeat treatment day 0 (Fig. 1). These patients were subsequently followed for another 2 visits (at weeks 1 and 4).

The study was performed in accordance with the principles of Good Clinical Practice guidelines. Ethics committee approvals and patients' written informed consents were obtained. The study was registered in the Clinical Trial Registry of India (CTRI/2010/091/000052).

\section{Concomitant Medications and Treatments}

Concomitant treatments and/or medications were allowed, except for the chronic use of narcotics; systemic corticosteroid(s); local corticosteroid injection into any joint or in the lower extremities; any surgery during the study that may affect the efficacy or safety objectives; viscosupplementation injected into any joint other than the knee(s); heparin or anti-vitamin $\mathrm{K}$ anticoagulant therapy; or use of any investigational drug, device, or biologic within 3 months. At each study visit, patients were asked if hylan G-F 20 treatment increased, decreased, or affected no change in use of other medications/therapies for the treatment of the target knee OA. Medications that patients were allowed to use for OA pain included paracetamol, aceclofenac, diacerein, lidocaine hydrochloride, ranitidine, calcium and calcium carbonate, tramadol, pantoprazole, glucosamine sulfate with or without chondroitin, and calcitriol.

\section{Study Outcomes}

The primary efficacy analysis was change in the WOMAC A1 subscore (walking pain) compared with baseline over 26 weeks with a single-injection of hylan G-F 20. In bilateral OA, only the target knee was included in the efficacy assessment.

Secondary efficacy analyses included evaluation of change from baseline in the WOMAC A (pain), WOMAC B (stiffness) and WOMAC C (physical function) subscales over 26 weeks and at weeks 39 and 52. The change in WOMAC A1 subscores were also evaluated at weeks 39 and 52. The PTGA is a global self-assessment of the patient's target knee OA using the Likert scale [ $0=$ very well, $1=$ well, $2=$ fair, $3=$ =poor, $4=$ =very poor]), and the COGA is the physician's global assessment of the patient's target knee OA using the same 5-point Likert scale. The 12Item SF-12 is a self-reported questionnaire that measures a patient's functional, physical, and mental health well-being. The PTGA and COGA scores were evaluated for change from baseline at weeks 1, 4, 12, 26, 39, and 52; SF-12 scores were analysed at 12,26 , and 52 weeks. 
Screening/Baseline

(Day 0)

Follow-up

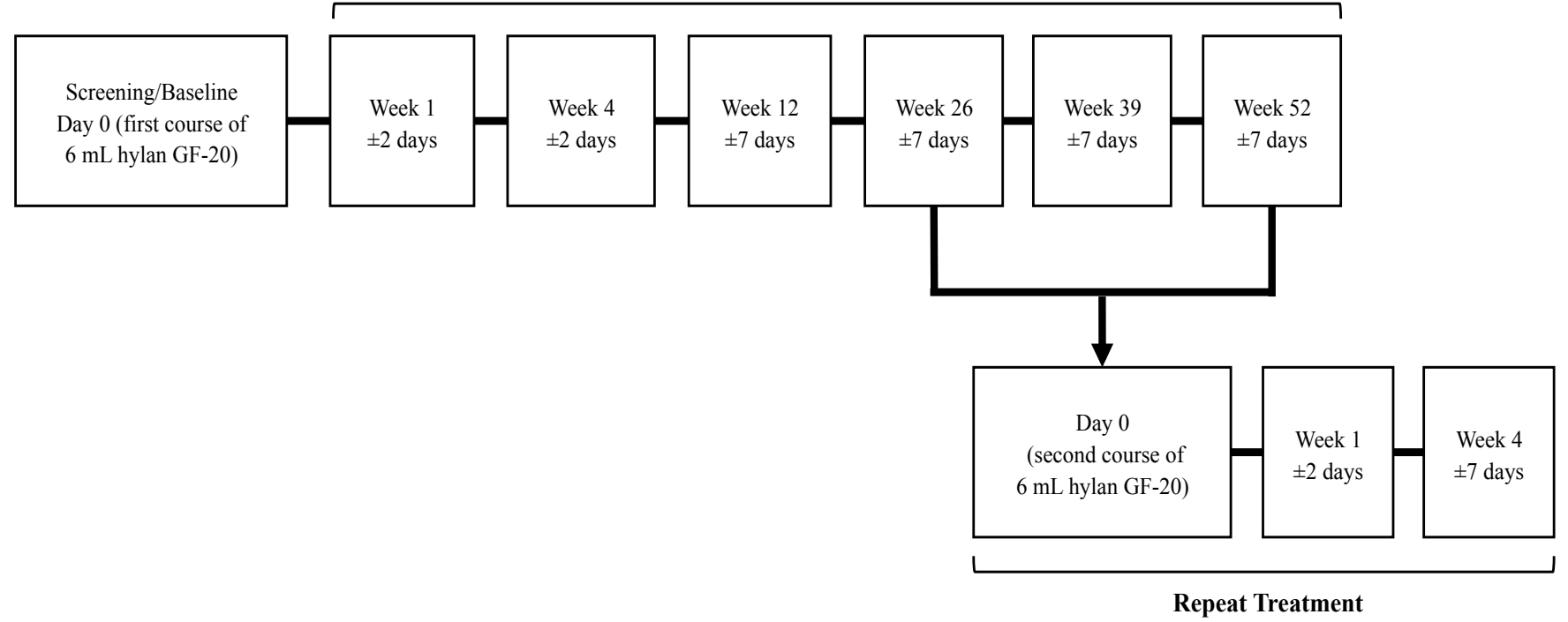

Fig. (1). Study design.

A $20 \%$ improvement over baseline was considered a conservative minimum clinically important improvement (MCII) for pain intensity rating [14], which was used to define the efficacy of hylan G-F 20 treatment for the primary efficacy analyses of change in WOMAC A1 scores.

Change of concomitant OA medication therapy, duration of time between the first course of hylan G-F 20 treatment and retreatment (if applicable), and change in WOMAC A1 scores during the repeat treatment phase were also analysed at repeat treatment weeks 1 and 4 . Changes in the repeat treatment phase were compared with the last value prior to repeat treatment. Subgroup analyses were performed for treatment efficacy and safety by age, gender, BMI, grade of OA, left or right knee injected, and/or duration of OA.

Safety was assessed with physical examinations, vital signs, and adverse events (AEs); safety monitoring occurred throughout the 52 weeks of the study. For bilateral treatments, both knees were analysed for safety. AEs were categorised as local AEs occurring in the treated joint, or systemic AEs occurring anywhere else.

\section{Statistical Analysis}

Statistical reports were generated using SAS version 9.1.3 (SAS Institute, Cary, NC, USA). Primary and secondary efficacy analyses were analysed using paired t-tests. McNemarBowkers tests were performed to analyse the change in the PTGA, COGA, and SF-12 scores and change in concomitant OA therapy analyses. A total of 360 patients provided $90 \%$ power to detect a change of $4.11 \mathrm{~mm}$ in the WOMAC A1 at 26 weeks compared with the baseline score with a 5\% significance level, assuming a standard deviation of $24 \mathrm{~mm}$. All primary and secondary efficacy analyses were performed on the intent-totreat (ITT) population (all patients who received at least 1 dose of the study medication) using paired t-tests (or Wilcoxon signed rank tests) to analyse continuous data from baseline.
Missing efficacy data were imputed using the last observation carried forward (LOCF) method.

Responder analyses were also performed at each follow-up visit. Responders were patients with $\geq 10-\mathrm{mm}$ reduction in WOMAC A1 score from baseline without any target knee AE, based on the reported minimal clinically important difference (MCID) for a $100 \mathrm{~mm}$ VAS scale, such as WOMAC A1 [15].

Additional pre-specified analyses were performed on 6 subgroups: gender, age, BMI, grade of knee OA, right or left knee injected, and the duration of OA. Sub-group analyses compared within and between the groups, using paired t-tests and ANOVA, respectively. For the BMI sub-analysis, the WOMAC A1 sub-score was analysed by normal $18.5-24.9 \mathrm{~kg} / \mathrm{m}^{2}$; overweight $\leq 25-30 \mathrm{~kg} / \mathrm{m}^{2}$; and obese $>30 \mathrm{~kg} / \mathrm{m}^{2}$. Patients were grouped by $\leq 0.25$ years, $>0.25$ to 2 years, $>2$ to $\leq 5$ years, $>5$ to $\leq 10$ years and $>10$ years for the duration of knee OA.

For safety analyses, AEs were categorised using MedDRA version 12.1; no imputation was performed for missing safety data.

\section{Ethics}

The study was conducted in accordance with the good clinical practice (GCP) guidelines. Investigators complied with the Declaration of Helsinki, GCP International Conference on Harmonisation of Technical Requirements for Registration of Pharmaceuticals for Human Use when developing the patient informed consent.

\section{RESULTS}

\section{Initial Treatment Phase}

\section{Patient Disposition}

At 36 sites in India, 394 patients were enrolled, received treatment, and were included in the ITT and safety 
Table 1. Demographics and baseline characteristics.

\begin{tabular}{|c|c|}
\hline Parameters & ITT Population $(\mathrm{N}=394) \mathrm{n}(\%)$ \\
\hline Number of Patients treated Bilaterally & $66(16.7)$ \\
\hline Number of Patients treated Unilaterally & $328(83.2)$ \\
\hline Age (years), mean $\pm \mathrm{SD}$ & $57.6 \pm 9.8^{*}$ \\
\hline Weight $(\mathrm{kg})$, mean $\pm \mathrm{SD}$ & $70.7 \pm 11.5$ \\
\hline Height $(\mathrm{cm})$, mean $\pm \mathrm{SD}$ & $160.1 \pm 8.8$ \\
\hline BMI $\left(\mathrm{kg} / \mathrm{m}^{2}\right)$, mean $\pm \mathrm{SD}$ & $27.7 \pm 4.5$ \\
\hline Normal (18.5-24.9) & $106(26.9)$ \\
\hline Overweight (25-30) & $199(50.6)$ \\
\hline Obese $(\geq 30.1)$ & $88(22.5)$ \\
\hline \multicolumn{2}{|l|}{ Gender } \\
\hline Male & $109(27.7)$ \\
\hline Female & $285(72.3)$ \\
\hline Time since OA diagnosis, months (years), mean \pm SD & $1.4 \pm 2.8$ \\
\hline Target Knee & n $(\%)$ \\
\hline Right Knee & $220(55.8)$ \\
\hline Left Knee & $174(44.2)$ \\
\hline Prior treatment/medications for target knee, repetition & $203(51.5)$ \\
\hline Anteroposterior and Lateral (OR) Anteroposterior and Skyline in target knee & $394(100)$ \\
\hline Femoro-patellar at $30^{\circ}$, repetition & $352(89.3)$ \\
\hline Kellgren-Lawrence grade in tibio-femoral compartment of the target knee & n (\%) \\
\hline Grade 1 & $20(5.1)$ \\
\hline Grade 2 & $151(38.3)$ \\
\hline Grade $3 * *$ & $223(56.6)$ \\
\hline Anaesthetics used in target knee (prior to the injection) & n (\%) \\
\hline Topical & $20(5.1)$ \\
\hline Local & $127(32.2)$ \\
\hline Approach used for injection & n (\%) \\
\hline Anterolateral & $1(0.3)$ \\
\hline Superolateral & $160(40.6)$ \\
\hline Superomedial & $116(29.4)$ \\
\hline Inferolateral & $78(19.8)$ \\
\hline Inferomedial & $39(9.9)$ \\
\hline Medical and Surgical History & n (\%) \\
\hline Cardiovascular diseases & $98(43.6)$ \\
\hline Musculoskeletal disorders & $79(35.1)$ \\
\hline Metabolic/endocrine/nutritional disorders & $77(34.2)$ \\
\hline
\end{tabular}

$* \mathrm{~N}$ for age is 392 as age was missing for 2 patients.

**1 patient with grade $4 \mathrm{OA}$ was included with the grade 3 patient group.

populations (Table 1). Of these, 369 (94\%) patients completed the study (Fig. 2).

\section{Patient Demographic and Baseline Characteristics}

Most patients $(n=285)$ in the ITT population were female, and were an average age of 58 years with a mean BMI of 28 $\mathrm{kg} / \mathrm{m}^{2}$ (Table 1). More than half of patients presented with grade 3 OA (Kellgren-Lawrence) with a mean time to diagnosis of 1.4 years. As only one patient had grade $4 \mathrm{OA}$, the patient was included with the grade $3 \mathrm{OA}$ patients for that subanalysis. The most commonly used concomitant medications and treatments are shown in Table 2 . The mean $\pm \mathrm{SD}$ for the baseline WOMAC A1 scores was $60.4 \pm 10.3 \mathrm{~mm}$. 


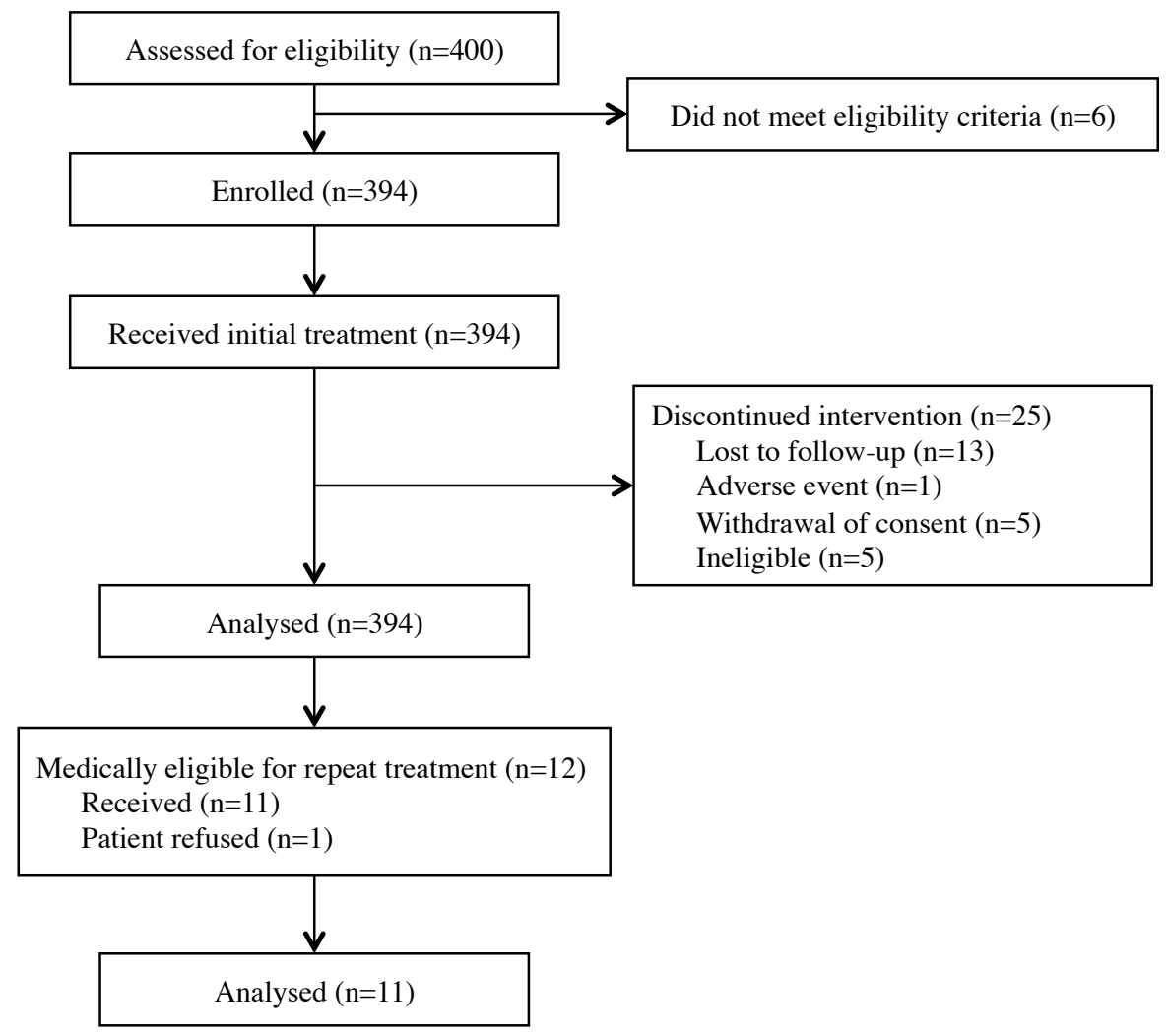

Fig. (2). Patient disposition.

Table 2. Most commonly used concomitant medications and treatments.

\begin{tabular}{|l|c|}
\hline \multicolumn{1}{|c|}{ Concomitant Medications } & n (\%) \\
\hline \hline Paracetamol & $130(33.0)$ \\
\hline Aceclofenac & $87(22.1)$ \\
\hline Diacerein & $81(20.6)$ \\
\hline Lidocaine Hydrochloride & $69(17.5)$ \\
\hline Ranitidine & $52(13.2)$ \\
\hline & $\mathbf{n}(\%)$ \\
\hline \hline Physiotherapy & $70(17.8)$ \\
\hline Kinesiotherapy & $43(10.9)$ \\
\hline Analgesic Intervention Supportive Therapy & $31(7.9)$ \\
\hline Cold Compress Therapy & $13(3.3)$ \\
\hline Diathermy & $13(3.3)$ \\
\hline Heat Therapy & $5(1.3)$ \\
\hline
\end{tabular}

\section{Treatment Efficacy}

Statistically significant decreases in the WOMAC A1 scores were observed from baseline to 26 weeks (primary endpoint) and 52 weeks with hylan G-F $20(\mathrm{p}<0.0001$ for both timepoints; Table $\mathbf{3}$ and Fig. 3A). By week 12, all WOMAC scores were reduced by $<20 \%$, demonstrating a MCII (Table 3 and Fig. 3A, 3B). Further reductions occurred as the study continued, with a moderately important $>30 \%$ reduction found for WOMAC A1 at week 52 (Table 3 and Fig. 3A). Significant improvements in the secondary endpoints of WOMAC A, B, and C sub-scores (Fig. 3B), and PTGA and COGA scores (Fig. 4A, 4B) were also observed from baseline to all time points $(\mathrm{p}<0.0001)$. As early as 1 week after hylan G-F 20 injection, significant changes from baseline in all efficacy parameters were observed (Table 3 and Fig. 3A, 3B).

Data from the PTGA scores demonstrated that a significantly $(\mathrm{p}<0.0001)$ higher percentage of patients rated their global OA condition as "well" or "very well" compared with their baseline score at each study visit (Fig. 4A). At baseline only, $15 \%$ of patients rated their global OA condition as "well" or "very well," versus almost $60 \%$ at week 26 and $65 \%$ at week 52 (Table 3 and Fig. 4A).

Over time, data from the COGA scores demonstrated that the clinicians rated a significantly $(p<0.0001)$ higher percentage of patients with a global OA condition as "well" or "very well" compared with their baseline score at each study visit. At baseline, 16\% rated the patient's global OA condition on the target knee as "well" or "very well," versus $60 \%$ and $64 \%$ of patients at weeks 26 and 52, respectively (Table 3 and Fig. 4B).

Similar trends were noted for the SF-12 data (Table 4). Compared with baseline scores, the proportion of patients that indicated their health status as "excellent" or "very good" was consistently higher for each study visit over the duration of the study, and responses to questions delineated improvement during the study. Patients also rated their feelings as more positive as the study continued. 
Table 3. Mean scores for efficacy parameters at each week.

\begin{tabular}{|c|c|c|c|c|c|c|c|}
\hline Statistics & Baseline $(n=394)$ & Week $1(n=394)$ & Week $4 \quad(n=394)$ & Week $12(n=394)$ & Week $26(n=394)$ & Week $39^{\dagger}(n=388)$ & Week $5^{\dagger}(n=388)$ \\
\hline \multicolumn{8}{|c|}{ Improvement of WOMAC A1 Sub-Score from Baseline } \\
\hline Mean \pm SD & - & $-11.8 \pm 16.5$ & $-18.5 \pm 18.4$ & $-25.1 \pm 19.1$ & $-28.0 \pm 19.9$ & $-30.1 \pm 21.4$ & $-32.7 \pm 20.0$ \\
\hline p value* & - & $<0.0001$ & $<0.0001$ & $<0.0001$ & $<0.0001$ & $<0.0001$ & $<0.0001$ \\
\hline \multicolumn{8}{|c|}{ Change of WOMAC A Score from Baseline } \\
\hline Mean \pm SD & - & $-10.2 \pm 13.9$ & $-17.6 \pm 16.2$ & $-23.1 \pm 17.7$ & $-25.7 \pm 18.6$ & $-26.3 \pm 20.1$ & $-29.2 \pm 19.2$ \\
\hline p value* & - & $<0.0001$ & $<0.0001$ & $<0.0001$ & $<0.0001$ & $<0.0001$ & $<0.0001$ \\
\hline \multicolumn{8}{|c|}{ Change of WOMAC B Score from Baseline } \\
\hline Mean \pm SD & - & $-9.61 \pm 16.4$ & $-15.3 \pm 19.4$ & $-20.9 \pm 21.9$ & $-22.9 \pm 22.0$ & $-23.6 \pm 22.9$ & $-25.7 \pm 22.0$ \\
\hline p value* & - & $<0.0001$ & $<0.0001$ & $<0.0001$ & $<0.0001$ & $<0.0001$ & $<0.0001$ \\
\hline \multicolumn{8}{|c|}{ Change of WOMAC C Score from Baseline } \\
\hline Mean \pm SD & - & $-9.5 \pm 13.1$ & $-15.7 \pm 15.8$ & $-20.9 \pm 18.5$ & $-22.6 \pm 19.8$ & $-23.3 \pm 20.5$ & $-25.7 \pm 19.5$ \\
\hline p value* & - & $<0.0001$ & $<0.0001$ & $<0.0001$ & $<0.0001$ & $<0.0001$ & $<0.0001$ \\
\hline \multicolumn{8}{|c|}{ Proportion of Patients in Each PTGA Score Rating, $n$ (\%) } \\
\hline Very well & $5(1.3)$ & $9(2.3)$ & $22(5.6)$ & $37(9.4)$ & $54(13.7)$ & $70(18.0)$ & $82(21.1)$ \\
\hline Well & $54(13.7)$ & 94 (23.9) & $126(32.0)$ & $165(41.9)$ & $179(45.4)$ & $178(45.9)$ & $175(45.1)$ \\
\hline Fair & $124(31.5)$ & $199(50.5)$ & $202(51.3)$ & $165(41.9)$ & $127(32.2)$ & $118(30.4)$ & $90(23.2)$ \\
\hline Poor & $183(46.4)$ & $89(22.6)$ & $40(10.2)$ & $26(6.6)$ & $32(8.1)$ & $21(5.4)$ & $40(10.3)$ \\
\hline Very poor & $25(6.3)$ & $3(0.8)$ & $4(1.0)$ & $1(0.3)$ & $2(0.5)$ & $1(0.3)$ & $1(0.3)$ \\
\hline Missing & $3(0.8)$ & $0(0.0)$ & $0(0.0)$ & $0(0.0)$ & $0(0.0)$ & $0(0.0)$ & $0(0.0)$ \\
\hline $\mathrm{p}$ value $* *$ & - & $<0.0001$ & $<0.0001$ & $<0.0001$ & $<0.0001$ & $<0.0001$ & $<0.0001$ \\
\hline \multicolumn{8}{|c|}{ Proportion of Patients in Each COGA Score Rating, $n$ (\%) } \\
\hline Very well & $9(2.3)$ & $15(3.8)$ & $28(7.1)$ & $38(9.6)$ & $56(14.2)$ & $68(17.5)$ & $77(19.8)$ \\
\hline Well & $55(14.0)$ & $102(25.9)$ & $142(36.0)$ & $181(45.9)$ & $181(45.9)$ & $179(46.1)$ & $177(45.6)$ \\
\hline Fair & $153(38.8)$ & $190(48.2)$ & $190(48.2)$ & $150(38.1)$ & $129(32.7)$ & $119(30.7)$ & $98(25.3)$ \\
\hline Poor & $172(43.7)$ & $84(21.3)$ & $33(8.4)$ & $24(6.1)$ & $27(6.9)$ & $21(5.4)$ & $35(9.0)$ \\
\hline Very poor & $5(1.3)$ & $3(0.8)$ & $1(0.3)$ & $1(0.3)$ & $1(0.3)$ & $1(0.3)$ & $1(0.3)$ \\
\hline $\mathrm{p}$ value $* *$ & - & $<0.0001$ & $<0.0001$ & $<0.0001$ & $<0.0001$ & $<0.0001$ & $<0.0001$ \\
\hline Statistics & & Week $1(n=390)$ & Week $4(n=390)$ & Week $12(n=378)$ & Week $26(n=372)$ & Week 39 $(n=362)$ & Week $52^{\dagger}(n=369)$ \\
\hline \multicolumn{8}{|c|}{ Proportion of Patients in Each Group of Concomitant OA Treatment and Medication, n (\%) } \\
\hline Increased therapy & - & $24(6.2)$ & $12(3.1)$ & $16(4.2)$ & $10(2.7)$ & $7(1.9)$ & $5(1.4)$ \\
\hline Decreased therapy & - & $59(15.1)$ & $57(14.6)$ & $33(8.7)$ & $33(8.9)$ & $3(0.8)$ & $2(0.5)$ \\
\hline No change in therapy & - & 307 (78.7) & $321(82.3)$ & $329(87.0)$ & $329(88.4)$ & $352(97.2)$ & $362(98.1)$ \\
\hline
\end{tabular}

*p value was calculated using paired t-test.

**p value was calculated using McNemar-Bowkers test.

${ }^{\dagger}$ Last Observation Carried Forward methodology was used. At Week 26, six patients received repeat treatment, which with LOCF, allowed data for 388 patients.

Throughout the study, the majority of patients did not report any change in use of concomitant medications. At weeks 26 and 52, $329(88 \%)$ and $362(98 \%)$ patients did not report any change in concomitant OA therapy, respectively.

No significant differences were found in the subgroup analysis by age ( $\mathrm{p}=0.9108$; ANOVA $)$ or gender $(\mathrm{p}=0.7039$; two sample t-test) from baseline to week 26. Patients with grades 1-3 OA all improved significantly from baseline to week 26; no significant differences were found between the 3 grades $(\mathrm{p}=0.8241$; ANOVA).
Significant differences were found for BMI classification, right or left knee injected, and duration of OA. Overweight patients had a greater decrease in the WOMAC A1 score from the baseline visit to week 26 when compared with normal and obese patients ( $\mathrm{p}=0.0005$ between groups). While injections in either knee alleviated walking pain as seen by decreased WOMAC A1 scores from baseline to week 26 , injected right knees had a greater decrease in mean WOMAC A1 score than injected left knees (-30.1 vs -25.4 , respectively, $\mathrm{p}<0.02)$. Analysis of patients by duration of $\mathrm{OA}$ 
(A)

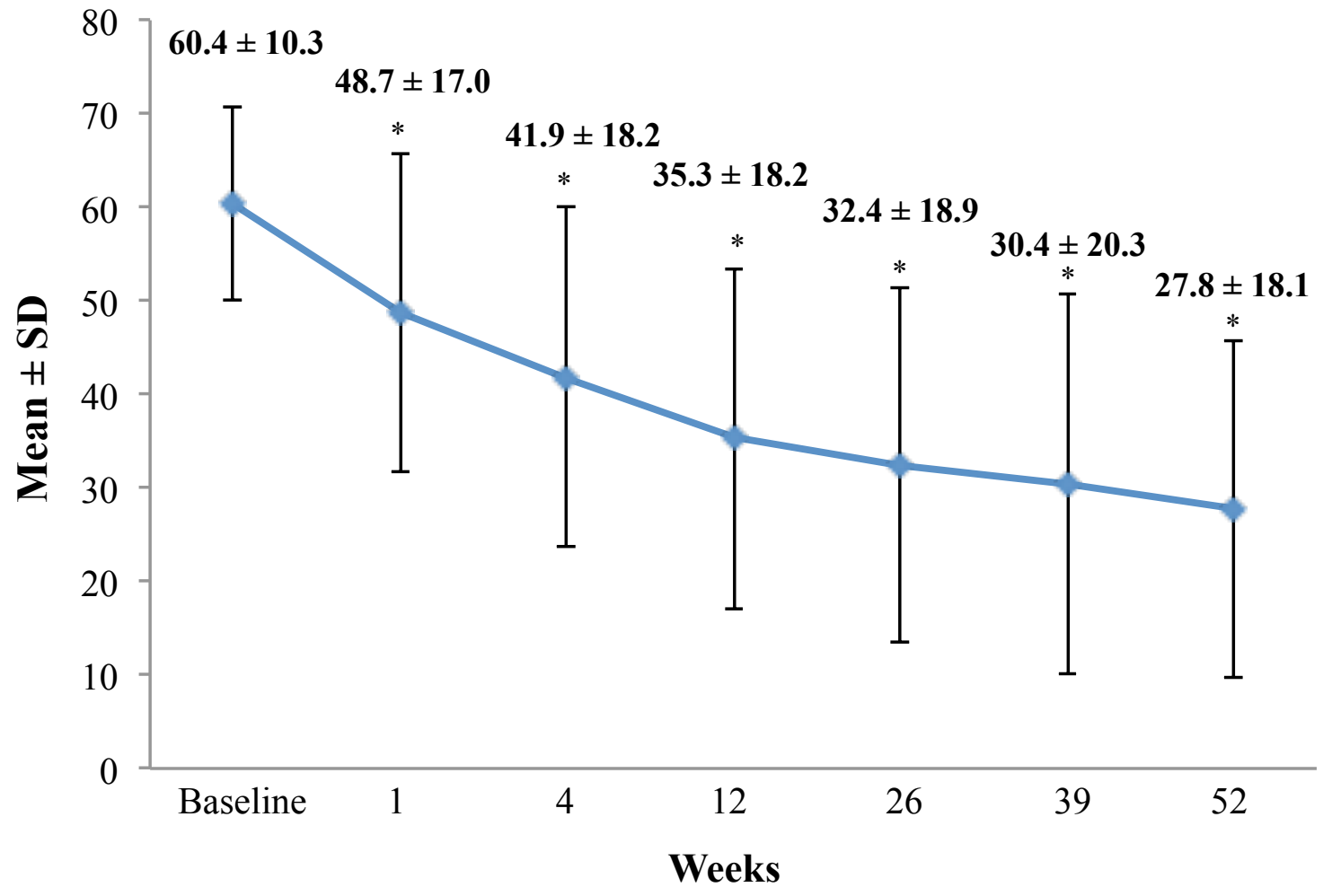

(B)

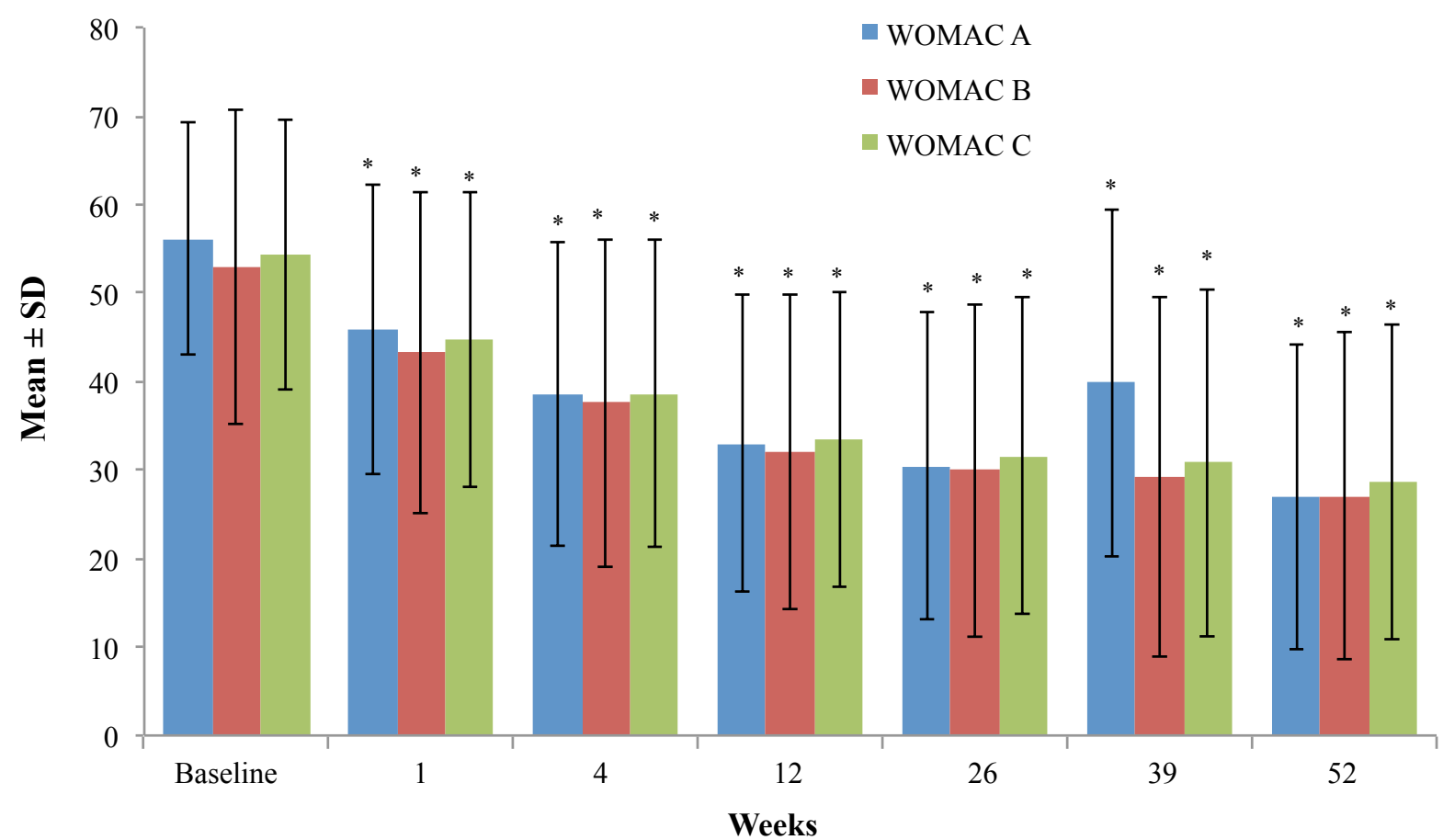

Fig. (3). Mean Scores for the WOMAC A1 (A) and the WOMAC A, B, and C scores (B) with hylan G-F 20 over time. *p $<0.0001$, mean change from baseline.

demonstrated that while all patients regardless of OA duration had significantly improved WOMAC A1 scores at week $26(\mathrm{p}<0.001)$, patients diagnosed with OA for $<0.25$ years had a greater improvement in WOMAC A1 scores from baseline compared with patients having OA for longer periods of time (ranging from $>0.25$ years to over 10 years, $\mathrm{p}<0.008)$. 
(A)

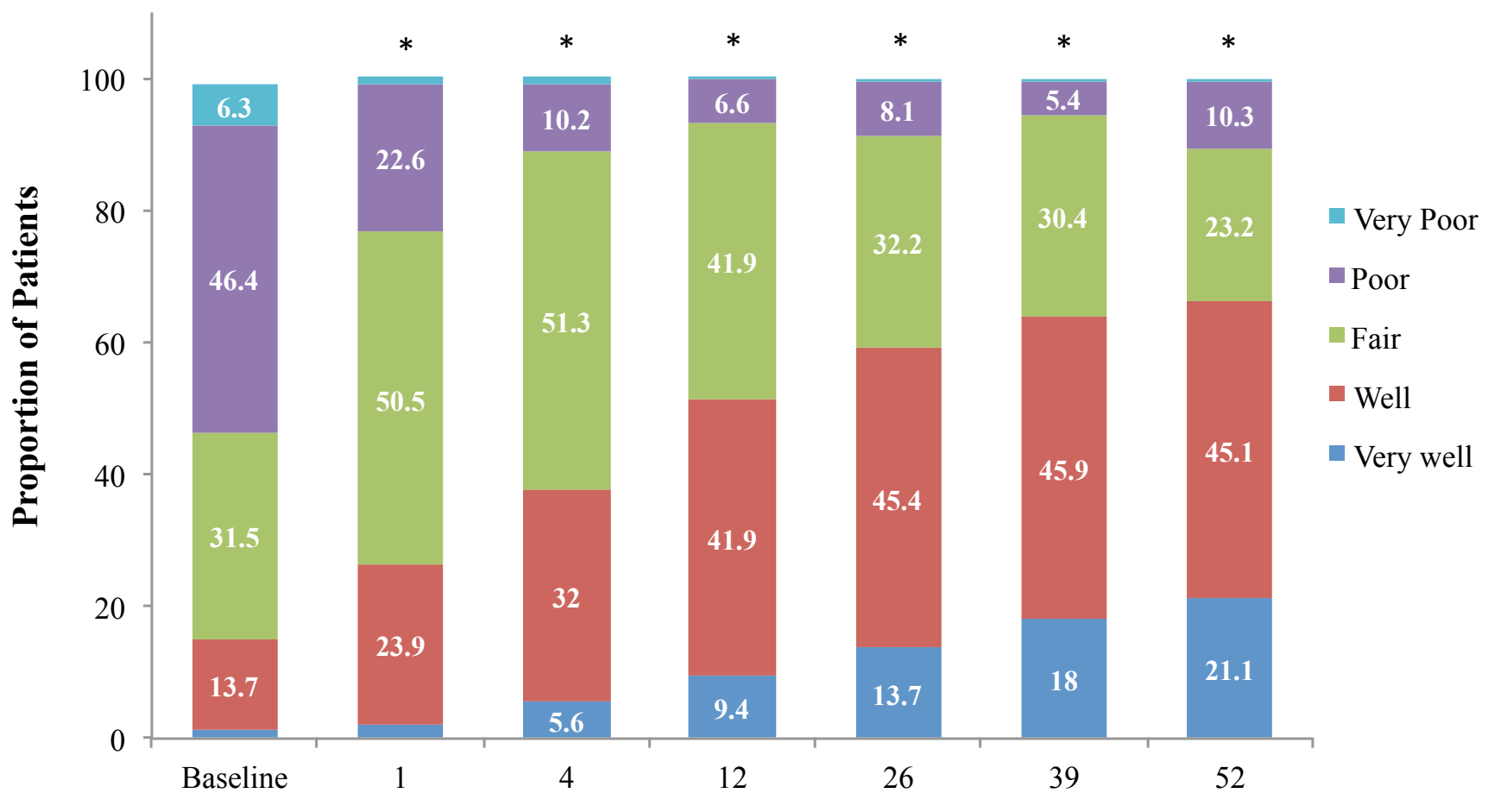

Weeks

(B)

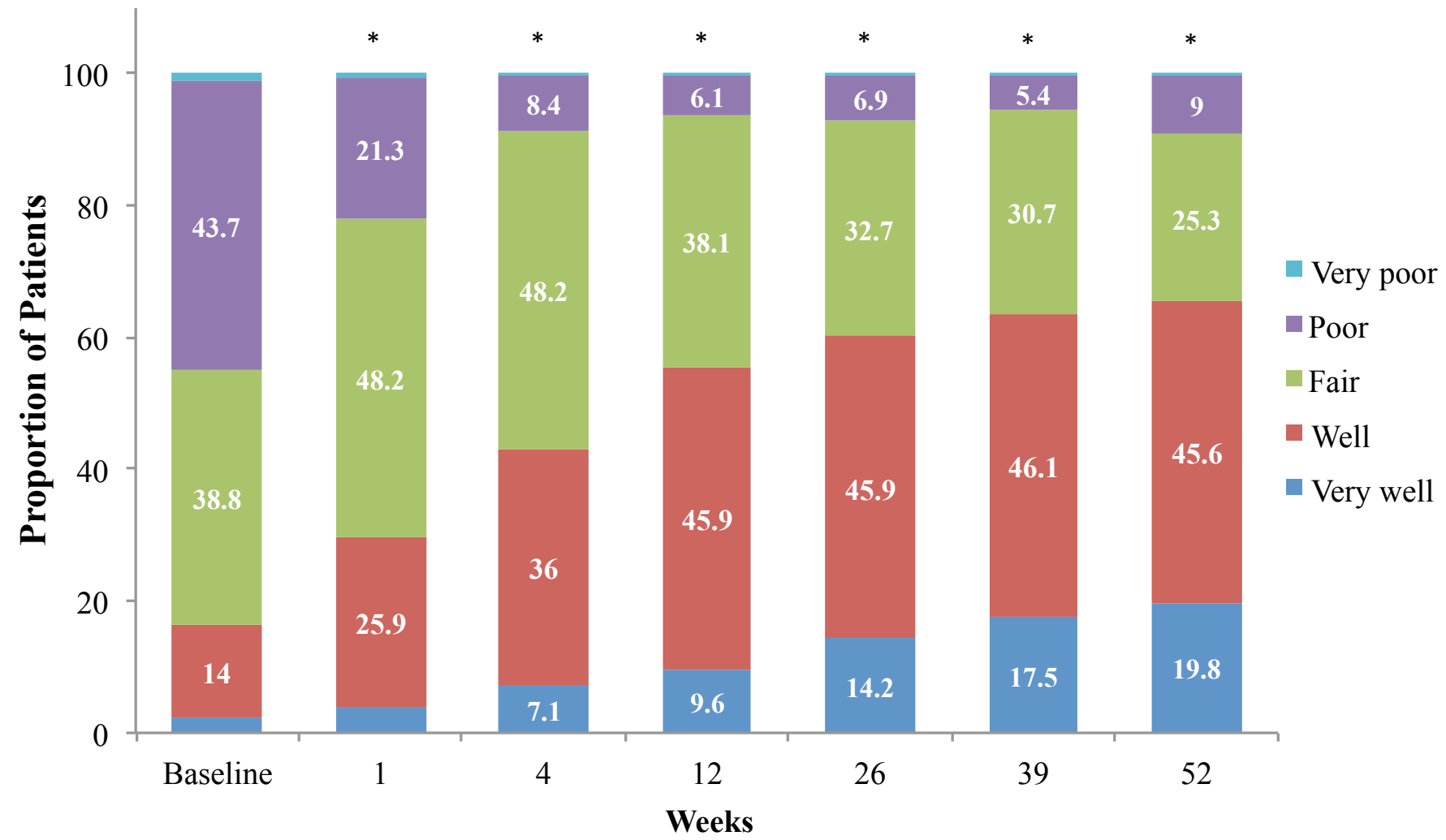

Fig. (4). The proportion of patients within each rating for PTGA (A) and COGA (B) scores with hylan G-F 20 over 52 weeks. *p<0.0001, mean change from baseline 
Table 4. Proportion of patients with responses for questions of the SF-12 at weeks 26 and 52.

\begin{tabular}{|c|c|c|c|}
\hline \multicolumn{4}{|c|}{ Question 1 Health Status } \\
\hline Excellent/Very Good & $35(8.9)$ & $87(22.1)$ & $135(34.8)$ \\
\hline Good & $139(35.3)$ & $230(58.4)$ & $189(48.7)$ \\
\hline \multicolumn{4}{|c|}{ Question 2a Moderate Activities } \\
\hline Yes, Limited a Lot/a Little & $367(93.1)$ & $303(76.9)$ & $293(75.5)$ \\
\hline No, Not Limited at All & $24(6.1)$ & $90(22.8)$ & $95(24.5)$ \\
\hline Missing & $3(0.8)$ & $1(0.3)$ & 0 \\
\hline No, Not Limited at All & $19(4.8)$ & $55(14.0)$ & $54(13.9)$ \\
\hline Missing & $2(0.5)$ & $1(0.3)$ & 0 \\
\hline \multicolumn{4}{|c|}{ Question 3a Less Accomplishment } \\
\hline All/Most of the Time & $152(38.6)$ & $62(15.7)$ & $76(19.6)$ \\
\hline Some of the Time & $163(41.4)$ & $170(43.1)$ & $142(36.6)$ \\
\hline A Little/None of the Time & $76(19.2)$ & $159(40.4)$ & $169(43.6)$ \\
\hline Missing & $3(0.8)$ & $3(0.8)$ & $1(0.3)$ \\
\hline \multicolumn{4}{|c|}{ Question 3b Limited in the Kind of Work or Other Activities } \\
\hline All/Most of the Time & $114(28.9)$ & $60(15.2)$ & $58(14.9)$ \\
\hline Some of the Time & $149(37.8)$ & $115(29.2)$ & $132(34.0)$ \\
\hline A Little/None of the Time & $128(32.5)$ & $217(55.1)$ & $198(51.0)$ \\
\hline Missing & $3(0.8)$ & $2(0.5)$ & 0 \\
\hline \multicolumn{4}{|c|}{ Question 4b Did Work or Other Activities } \\
\hline All/Most of the Time & $88(22.3)$ & $48(12.2)$ & $56(14.4)$ \\
\hline Some of the Time & $166(42.1)$ & $131(33.2)$ & $128(33.0)$ \\
\hline A Little/None of the Time & $137(34.8)$ & $213(54.1)$ & $204(52.6)$ \\
\hline Missing & $3(0.8)$ & $2(0.5)$ & 0 \\
\hline \multicolumn{4}{|c|}{ Question 5 Pain Interfered with Your Normal Work } \\
\hline Not at All/A Little Bit & $70(17.8)$ & $207(52.5)$ & $219(56.4)$ \\
\hline Moderately & $182(46.2)$ & $122(31.0)$ & $105(27.1)$ \\
\hline Quite a Bit/Extremely & $140(35.5)$ & $63(16.0)$ & $64(16.5)$ \\
\hline Missing & $2(0.5)$ & $2(0.5)$ & 0 \\
\hline
\end{tabular}




\begin{tabular}{|c|c|c|c|}
\hline SF-12 & $\begin{array}{c}\text { Baseline Visit }(\mathrm{N}=394) \\
\text { n (\%) }\end{array}$ & $\begin{array}{c}\text { Week } 26(\mathrm{~N}=394) \\
\text { n }(\%)\end{array}$ & $\begin{array}{c}\text { Week } 52 \%(\mathrm{~N}=388) \\
\text { n }(\%)\end{array}$ \\
\hline All/Most of the Time & $188(47.7)$ & $240(60.9)$ & $244(62.9)$ \\
\hline Some of the Time & $112(28.4)$ & $106(26.9)$ & $121(31.2)$ \\
\hline Missing & $2(0.5)$ & $2(0.5)$ & 0 \\
\hline \multicolumn{4}{|c|}{ Question 6b Having a Lot of Energy } \\
\hline All/Most of the Time & $122(31.0)$ & $190(48.2)$ & $215(55.4)$ \\
\hline Some of the Time & $154(39.1)$ & $134(34.0)$ & $132(34.0)$ \\
\hline All/Most of the Time & $67(17.0)$ & $28(7.1)$ & $53(13.7)$ \\
\hline Some of the Time & $162(41.1)$ & $102(25.9)$ & $107(27.6)$ \\
\hline A Little/None of the Time & $159(40.4)$ & $261(66.2)$ & $227(58.5)$ \\
\hline Missing & $6(1.5)$ & $3(0.8)$ & $1(0.3)$ \\
\hline \multicolumn{4}{|c|}{ Question 7 Physical Health or Emotional Problems } \\
\hline All/Most of the Time & $116(29.4)$ & $35(8.9)$ & $43(11.1)$ \\
\hline Some of the Time & $166(42.1)$ & $129(32.7)$ & $119(30.7)$ \\
\hline A Little/None of the Time & $110(27.9)$ & $228(57.9)$ & $226(58.2)$ \\
\hline
\end{tabular}

*Last Observation Carried Forward methodology was used. At Week 26, six patients received repeat treatment, which with LOCF, allowed data for 388 patients.

\section{Responder Analysis}

The number (\%) of responders was evaluated at each post-baseline visit, and increased from $42.9 \%$ at week 1 to $80.7 \%$ at week 52 (Fig. 5).

\section{Repeat Treatment Phase}

A total of 12 patients among the 394 within the ITT population (6 patients each at weeks 26 and 52) were eligible for repeat treatment because of recurring knee OA pain; 1

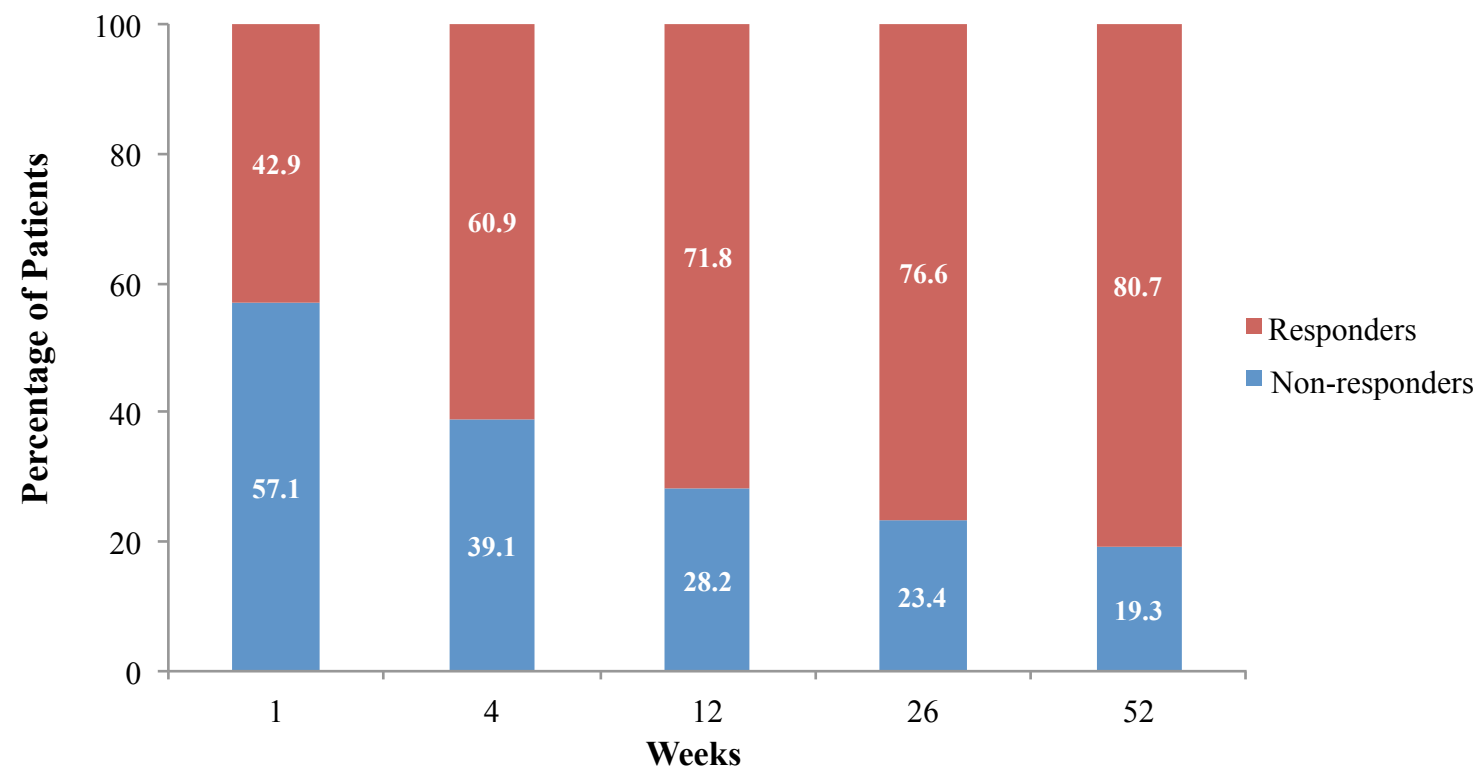

Fig. (5). Responder rates at weeks 1, 4, 12, 26, and 52 following hylan G-F 20. Responders were patients with $\geq 10 \mathrm{~mm}$ WOMAC A1 score reduction from baseline. 
Table 5. Repeat treatment scores and change in scores for the 11 patients who were retreated.

\begin{tabular}{|c|c|c|c|}
\hline Score & $\operatorname{Mean} \pm$ SD & Mean Change from Repeat Day 0 & $P$ Value \\
\hline \multicolumn{4}{|l|}{ WOMAC A1 } \\
\hline Repeat Week 1 & $49.5 \pm 16.2$ & -12.4 & 0.02 \\
\hline Repeat Week 4 & $51.7 \pm 8.5$ & -10.1 & 0.03 \\
\hline \multicolumn{4}{|l|}{ WOMAC A } \\
\hline Repeat Day 0 & $52.9 \pm 14.1$ & - & - \\
\hline Repeat Week 1 & $48.9 \pm 11.4$ & -4.0 & 0.23 \\
\hline Repeat Week 4 & $49.8 \pm 5.7$ & -3.1 & 0.47 \\
\hline \multicolumn{4}{|l|}{ WOMAC B } \\
\hline \multicolumn{4}{|l|}{ WOMAC C } \\
\hline Repeat Day 0 & $53.4 \pm 7.2$ & - & - \\
\hline Repeat Week 1 & $49.3 \pm 8.8$ & -4.1 & 0.10 \\
\hline Repeat Week 4 & $48.7 \pm 7.4$ & -4.7 & 0.03 \\
\hline
\end{tabular}

refused treatment at week 52. Hence, 11 patients were considered for repeat analyses over 4 weeks. The mean \pm SD duration between the first treatment and retreatment was 38.3 \pm 13.4 weeks (median=27.4 weeks, range $=26.0$ to 53.0 weeks).

A significant decrease in WOMAC A1 subscore was observed from retreatment day 0 to repeat week 1 and 4 (Table 5). Mean changes for the other WOMAC sub-scale scores are shown in Table $\mathbf{5 .}$

Statistically significant improvements occurred in PTGA scores from repeat day 0 to repeat week 1 and $4(p<0.03$ for both). At repeat week 4, while none of the patients rated their PTGA score as "well," $81.8 \%$ patients rated their PTGA score as "fair" and only $18.2 \%$ rated their PTGA score as "poor" compared with $36.4 \%$ patients and $63.6 \%$ patients at repeat day 0 , respectively. Per COGA scoring, $9.1 \%$ patients were rated as "well," $63.6 \%$ as "fair," and $27.3 \%$ as "poor" at repeat week 4 compared with $0 \%, 27.3 \%$, and $72.7 \%$ patients at repeat day 0 , respectively. Data from the SF-12 questionnaire during the repeat treatment phase showed that compared with repeat day 0 , a numerically higher proportion of patients at repeat week 4 indicated their health status was "very good" or "good," and no patient rated his or her health status as "poor" at the final repeat treatment visit. Results from other SF-12 questions showed no change over the 4 weeks of the repeat treatment phase.

\section{Safety Analysis}

Twenty-three $(6 \%)$ patients reported 26 local target knee AEs; arthralgia (16 patients [4\%]) and synovitis (4 patients [1\%]) were the most common local AEs. Other local target knee AEs were arthritis, bursitis, musculoskeletal stiffness, injection site pain, and injection site pruritus (1 patient [0.3\%] each). Of the 26 local AEs, 10 (3\%) were considered treatment-related and/or procedure-related; arthralgia (4 patients $[17 \%])$, synovitis (4 patients [17\%]), musculoskeletal stiffness (1 patient [4\%]) and injection site pain (1 patient [4\%]). None of the local target knee AEs were fatal; 6 patients experienced moderate to severe local AEs; arthralgia (3 patients [13\%]), synovitis (2 patients $[9 \%])$, and arthritis (1 patient $[4 \%])$.

Twenty-eight (7\%) patients reported 46 systemic AEs. Of these patients, 4 reported AEs (1 patient each reported oedema peripheral, cellulitis, rash, or swelling of the face) that were considered by the investigator to be related to the study treatment. A total of 6 patients $(2 \%)$ had 9 serious AEs (SAEs). One patient had a local SAE; this patient developed advanced arthritis in the non-target knee and underwent a total knee replacement. This SAE was considered unrelated to study treatment or procedure. Five $(1.3 \%)$ patients had 8 systemic SAEs, which were all considered not related to the study treatment or procedure. One patient each reported coronary artery disease, cardiac arrest, urinary tract infection, or influenza. The fifth patient reported multiple SAEs, including cervical myelopathy, cervical spinal stenosis, intervertebral disc protrusion, and myelomalacia of cervical cord. All systemic SAEs were resolved except for coronary artery disease and cardiac arrest. The patient with coronary artery disease recovered with sequelae while the patient with cardiac arrest was reported as fatal. There were no clinically significant findings for vital signs and physical examinations.

None of the 11 retreated patients reported any AEs or SAEs during the 4-week retreatment phase. 


\section{DISCUSSION}

The present open-label, multicentre, phase 4 study showed that a single, 6-mL hylan G-F 20 injection was safe and efficacious up to 26 weeks in patients with symptomatic OA of the knee. The OASIS study continued for 52 weeks, and hylan G-F 20 remained safe and efficacious throughout the entire year of the study. Repeat treatment was also shown to be safe and efficacious for 4 weeks after a second injection.

The efficacy of single-injection 6-mL hylan G-F 20 treatment was demonstrated by significant improvements from baseline in all the efficacy parameters, including the primary endpoint of WOMAC A1 at week 26. Improvements in the WOMAC A, B, and C subscores, PTGA, and COGA were consistent with the WOMAC A1. Significant changes in all efficacy parameters measured were observed as early as 1 week after injection. In addition, a higher proportion of patients reported improvements in the quality of life (SF-12) parameters at 26 weeks after a single injection of hylan G-F 20.

Statistically significant improvements in all the efficacy parameters in this study were consistent with the findings of 2 previous studies $[9,10]$. In those studies, statistically significant improvements in WOMAC A1, WOMAC A, PTGA, and COGA scores were observed over 26 weeks with the treatment of a single, 6-mL injection of hylan G-F 20 [9, $10]$.

A large, multicentre trial of a single, $6-\mathrm{mL}$ injection of hylan G-F 20 compared with placebo found a significantly better improvement in their primary endpoint of a WOMAC A (pain) subscore over 26 weeks [9]. A 36\% mean change from baseline to week 26 with a single, 6 -mL hylan G-F 20 treatment was reported for WOMAC A [9], which is less than the mean change from baseline to week 26 for the WOMAC A score of $46 \%$ in our OASIS study. For the primary endpoint of WOMAC A1 (walking pain) score improvement in this study, mean scores were significantly reduced by $54 \%$ at week 52 . The reduction in WOMAC A1 scores as early as week $12(42 \%)$ met the MCII criteria of a $20 \%$ improvement over baseline [14].

A pronounced placebo effect with intra-articular injections (ES $0.73,95 \%$ CI $0.56,0.91$ ) has been reported in a recent meta-analysis of the placebo effect in OA treatments [16]. Chevalier and colleagues reported a large placebo effect of $29 \%$ in the 6-mL hylan G-F $20 v$ s placebo trial [9]. Even with this large placebo effect, a statistically significant treatment difference for hylan G-F 20 was found, with a greater pain reduction based on the $36 \%$ mean change from baseline over the 26-week study [9].

Taken together, the Chevalier study demonstrated clinically important reductions in pain intensity with a single, 6-mL hylan G-F 20 treatment vs placebo [9]. Results from our OASIS study found similar clinically important improvements after the same hylan G-F 20 treatment. This MCII with hylan G-F 20 treatment was evident from week 4 through week 52, based on $>20 \%$ improvement seen in the primary outcome. In addition, the percentage of responders almost doubled from week 1 to week 52, with $81 \%$ of patients responding to hylan G-F 20 treatment at the end of study timepoint (Fig. 5).

Also, very few patients had a change in their concomitant OA therapy, with only $5(1.4 \%)$ needing an increase in OA therapy. Because pain and function scores improved from baseline at 26 and 52 weeks, without an increased intake of analgesics, these data further suggest that the improvements occurred because hylan G-F 20 was effective in alleviating pain and improving function, and was not just because of a placebo effect.

NSAIDs are typically used as a first line pharmacotherapeutic option to alleviate knee OA pain [1, 17]. Because of increased gastrointestinal (GI) risks and other potential safety concerns with NSAIDs [18], the labeling of all NSAIDs require a boxed warning regarding potential adverse effects $[19,20]$. Thus, the use of a local therapy, such as hylan G-F 20, with mostly local side effects, may be a better option for treating knee OA pain than NSAIDs.

Hylan G-F 20 has been shown to be just as effective as NSAIDs. In a comparison study of hylan G-F 20, NSAIDs, and hylan G-F 20 + NSAIDs at 26 weeks, outcome measures were significantly improved with hylan G-F 20 + NSAIDs compared with NSAIDs alone [21]. Another study found significantly improved WOMAC A scores for the hylan G-F 20 group compared with control and NSAID [22].

Other studies of hylan G-F 20 have also demonstrated lower GI AEs versus NSAIDs, and less need for NSAID use with hylan G-F 20 treatment. In a randomised, controlled trial comparing 3 weekly $2-\mathrm{mL}$ injections of hylan G-F 20 with placebo, Wobig et al. demonstrated significant improvements for patients treated with hylan G-F 20, with significantly less need for NSAID rescue therapy than those in the placebo group [23]. Similarly, Raynauld et al. compared a group of patients treated with appropriate care, which included NSAIDs, with a group of patients treated with hylan G-F 20 plus appropriate care [24]. In this study, those whose treatment included hylan G-F 20 had fewer GI AEs compared with those in the appropriate care alone group [24]. Finally, another randomised, controlled trial reported significantly fewer GI AEs for the hylan G-F 20 group than those taking NSAIDs or placebo [22].

Although only 11 patients were eligible and willing to receive a second single hylan G-F 20 injection, all patients treated with a repeat course of therapy had significant improvements in WOMAC A1 scores and most of the other efficacy parameters from the time of repeat injection for 4 weeks after injection. Consistent with a previous study of repeat use of a single injection, hylan G-F 20 repeat injection was effective for 4 weeks after the first injection [9].

While the WOMAC A1 scores of all patient groups significantly improved $(\mathrm{p}<0.0001)$ from baseline to 26 weeks, subgroup analyses showed that hylan G-F 20 efficacy was better for patients with a shorter $(\leq 0.25$ years) versus longer $(>0.25$ to $>10$ years) duration of OA symptoms. Patients with grade 1,2 , or 3 OA significantly improved from baseline to 26 weeks in the WOMAC A1 score, with no observed change between the different knee grades $(\mathrm{p}=0.8241)$. With regards to BMI, overweight patients had a significantly higher change in WOMAC Al scores from 
baseline to week 26 compared with normal and obese patients $(\mathrm{p}=0.0005)$. Interestingly, the change in WOMAC A1 scores from baseline to week 26 was higher for injected right knees compared with injected left knees $(p=0.02)$. Gender and age were also analysed, but no differences were found for these sub-groups for the initial study from baseline to week 26. Given the small number of patients within some of the sub-groups, the results from these sub-group analyses should be interpreted with caution.

A single injection of 6-mL hylan G-F 20 was found to be well tolerated with no study drug or procedure-related SAEs, or any unexpected events. The one patient fatality reported in the study was not related to hylan G-F 20 injection or treatment procedure. During the study, only 6\% (23/394) of patients reported a local AE. This low incidence of local AEs is consistent with previous clinical reports of a single injection of hylan G-F 20 [9, 10]. No additional AEs were reported after repeat treatment with of hylan G-F 20. Our findings are consistent with previously published studies in which a repeated dose of hylan G-F 20 had an appropriate safety profile for continued treatment of patients with knee OA $[24,25]$.

Limitations of our study include the open-label design with no direct comparator resulting in potential bias. The design of this post-marketing study was intentionally openlabel, as efficacy has been shown with single-injection hylan G-F 20 compared with placebo for 26 weeks [9]. This study design has the advantage of being closer to the real world clinical experience than a rigourous clinical trial. Also, comparison of a viscosupplement with placebo may not demonstrate its full efficacy given the increasing magnitude of the placebo effect in OA studies over the years. Many clinical studies of viscosupplementation determine the efficacy of the treatment by comparing each patient's improvement from baseline to follow-up [7-9, 22, 26-51]. Thus, the open-label design evaluates the clinically relevant patient reported pain reduction, helping to demonstrate realworld experience.

Another limitation as mentioned above is that the study was not powered for subgroup analyses, so the subanalysis results should be interpreted with caution. Finally, the number of patients who received repeat treatment is limited $(n=11)$, which limits the strength of our conclusions with regard to repeat treatment.

\section{CONCLUSION}

In this open-label, multicentre study, a single, 6-mL IA injection of hylan G-F 20 was well tolerated and efficacious in providing statistically significant improvements from baseline in all outcome measures over a 52-week period in patients with symptomatic knee OA. To our knowledge, this is the first report of a single-injection viscosupplement showing both efficacy and safety over 52 weeks.

\section{LIST OF ABBREVIATIONS}

$\begin{array}{ll}\mathrm{AEs} & =\text { Adverse events } \\ \mathrm{AP} & =\text { Anterioposterior } \\ \mathrm{COGA} & =\text { Clinical Observer Global Assessment }\end{array}$
ES
$=$ Effect size
IA $\quad=$ Intra-articular
ITT $=$ Intent-to-treat
$\mathrm{OA}=$ Osteoarthritis
$\begin{aligned} \text { OASIS }= & \text { Osteoarthritis Synvisc-One }{ }^{\circledR} \text { Indian Post- } \\ & \text { Marketing Study }\end{aligned}$
PTGA $=$ Patient Global Assessment
$\mathrm{RV} \quad=$ Repeat visit
$\mathrm{SAE} \quad=$ Serious adverse event
SF-12 = Short form-12
VAS $=$ Visual analogue scale
WOMAC $=$ Western Ontario and McMaster Universities Osteoarthritis Index

\section{CONFLICT OF INTEREST}

This manuscript is based on clinical trial results from a study sponsored by Genzyme Biosurgery (now Sanofi). Drs. S. Pal, S. Thuppal, K. Reddy, S. Avasthi, and A. Aggarwal received grants and research support from Genzyme Biosurgery (now Sanofi). H. Bansal and Dr. S. Mohanasundaram are employees of Sanofi. Dr. F. Bailleul is a former employee of Genzyme Biosurgery (now Sanofi). Genzyme India Pvt Ltd and Sanofi provided support for the medical writing assistance of Gunjan Agarwal, PhD (Max Neeman International) and Susan Bijur (Precise Publications), respectively.

\section{ACKNOWLEDGEMENTS}

The authors acknowledge the medical writing assistance of Gunjan Agarwal, PhD (Max Neeman International) and Susan Bijur, PhD (Precise Publications, LLC) supported by by Genzyme India Pvt Ltd and Sanofi, respectively.

All authors participated in data management, data interpretation, input into manuscript content, manuscript preparation, and approved of the final version of the manuscript.

\section{REFERENCES}

[1] Zhang W, Nuki G, Moskowitz RW, et al. OARSI recommendations for the management of hip and knee osteoarthritis: part III: Changes in evidence following systematic cumulative update of research published through January 2009. Osteoarthr Cartil 2010; 18: 476-99.

[2] Fransen M, Bridgett L, March L, Hoy D, Penserga E, Brooks P. The epidemiology of osteoarthritis in Asia. Int J Rheum Dis 2011; 14: 113-21.

[3] Misra A, Shrivastava U. Obesity and dyslipidemia in South Asians. Nutrients 2013; 5: 2708-33.

[4] Balazs E. Viscoelastic properties of hyaluronic acid and biological lubrication. Univ Mich Med Cent J 1968; pp. 255-9.

[5] Balazs EA, Denlinger JL. Viscosupplementation: a new concept in the treatment of osteoarthritis. J Rheumatol 1993; 20(Suppl 39): 39.

[6] Wobig M, Bach G, Beks P, et al. The role of elastoviscosity in the efficacy of viscosupplementation for osteoarthritis of the knee: a comparison of hylan G-F 20 and a lower- molecular-weight hyaluronan. Clin Ther 1999; 21: 1549-62. 
[7] Scale D, Wobig M, Wolpert W. Viscosupplementation of osteoarthritic knees with hylan: a treatment schedule study. Curr Ther Res 1994; 55: 220-32.

[8] Cubukcu D, Ardic F, Karabulut N, Topuz O. Hylan G-F 20 efficacy on articular cartilage quality in patients with knee osteoarthritis: clinical and MRI assessment. Clin Rheumatol 2005; 24: 336-41.

[9] Chevalier X, Jerosch J, Goupille P, et al. Single, intra-articular treatment with $6 \mathrm{ml}$ hylan G-F 20 in patients with symptomatic primary osteoarthritis of the knee: a randomised, multicentre, double-blind, placebo controlled trial. Ann Rheum Dis 2010; 69: 113-9.

[10] Conrozier T, Jerosch J, Beks P, et al. Prospective, multi-centre, randomised evaluation of the safety and efficacy of five dosing regimens of viscosupplementation with hylan G-F 20 in patients with symptomatic tibio-femoral osteoarthritis: a pilot study. Arch Orthop Trauma Surg 2009; 129: 417-23.

[11] Caborn D, Rush J, Lanzer W, Parenti D, Murray C. A randomized, single-blind comparison of the efficacy and tolerability of hylan GF 20 and triamcinolone hexacetonide in patients with osteoarthritis of the knee. J Rheumatol 2004; 31: 333-43.

[12] Raman R, Dutta A, Day N, Sharma HK, Shaw CJ, Johnson GV. Efficacy of hylan G-F 20 and sodium hyaluronate in the treatment of osteoarthritis of the knee -- a prospective randomized clinical trial. Knee 2008; 15: 318-24.

[13] Synvisc-One ${ }^{\circledR}$ (hylan G-F 20) Prescribing Information. Genzyme Biosurgery.

[14] Dworkin RH, Turk DC, McDermott MP, et al. Interpreting the clinical importance of group differences in chronic pain clinical trials: IMMPACT recommendations. Pain 2009; 146: 238-44.

[15] Wandel S, Juni P, Tendal B, et al. Effects of glucosamine, chondroitin, or placebo in patients with osteoarthritis of hip or knee: network meta-analysis. BMJ 2010; 341: c4675.

[16] Zhang W, Robertson J, Jones AC, Dieppe PA, Doherty M. The placebo effect and its determinants in osteoarthritis: meta-analysis of randomised controlled trials. Ann Rheum Dis 2008; 67: 171623.

[17] Hochberg MC, Altman RD, April KT, et al. American College of Rheumatology 2012 recommendations for the use of nonpharmacologic and pharmacologic therapies in osteoarthritis of the hand, hip, and knee. Arthritis Care Res (Hoboken) 2012; 64: 465-74.

[18] Conaghan PG. A turbulent decade for NSAIDs: update on current concepts of classification, epidemiology, comparative efficacy, and toxicity. Rheumatol Int 2012; 32: 1491-502.

[19] FDA. Acetaminophen Dosage Announcement. Available from: http://www_medicaid.nv.gov/Downloads/provider/web_announcem ent_468_20120425.pdf [Accessed January 14, 2013].

[20] FDA. Information for Healthcare Professionals: Non-Selective Non-Steroidal Anti-Inflammatory Drugs (NSAIDs)*. http://www. fda.gov/Drugs/DrugSafety/PostmarketDrugSafetyInformationforPa tientsandProviders/DrugSafetyInformationforHeathcareProfessiona 1s/ucm085282.htm [Accessed January 14, 2013].

[21] Adams ME, Atkinson MH, Lussier AJ, et al. The role of viscosupplementation with hylan G-F 20 (Synvisc) in the treatment of osteoarthritis of the knee: a Canadian multicenter trial comparing hylan G-F 20 alone, hylan G-F 20 with non-steroidal anti- inflammatory drugs (NSAIDs) and NSAIDs alone. Osteoarthr Cartil 1995; 3: 213-25.

[22] Dickson DJ, Hosie G, English JR. A double-blind, placebocontrolled comparison of hylan G-F 20 against diclofenac in knee osteoarthritis. J Clin Res 2001; 4: 41-52.

[23] Wobig M, Beks P, Dickhut A, Maier R, Vetter G. Open-label multicenter trial of the safety and efficacy of viscosupplementation with hylan G-F 20 (Synvisc) in primary osteoarthritis of the knee. J Clin Rheumatol 1999; 5(Suppl): S24-S31.

[24] Raynauld JP, Goldsmith CH, Bellamy N, et al. Effectiveness and safety of repeat courses of hylan G-F 20 in patients with knee osteoarthritis. Osteoarthr Cartil 2005; 13: 111-9.

[25] Waddell DD, Cefalu CA, Bricker DC. An open-label study of a second course of hylan G-F 20 for the treatment of pain associated with knee osteoarthritis. Curr Med Res Opin 2003; 19: 499-507.

[26] Wobig M, Dickhut A, Maier R, Vetter G. Viscosupplementation with hylan G-F 20: a 26-week controlled trial of efficacy and safety in the osteoarthritic knee. Clin Ther 1998; 20: 410-23.

[27] Kotevoglu N, Iybozkurt PC, Hz O, Toktas H, Kuran B. A prospective randomised controlled clinical trial comparing the efficacy of different molecular weight hyaluronan solutions in the treatment of knee osteoarthritis. Rheumatol Int 2006; 26: 325-30.

[28] Diracoglu D, Vural M, Baskent A, Dikici F, Aksoy C. The effect of viscosupplementation on neuromuscular control of the knee in patients with osteoarthritis. J Back Musculoskelet Rehabil 2009; 22: $1-9$.

[29] Grecomoro G, Martorana U, Di Marco C. Intra-articular treatment with sodium hyaluronate in gonarthrosis: a controlled clinical trial versus placebo. Pharmatherapeutica 1987; 5: 137-41.

[30] Corrado EM, Peluso GF, Gigliotti S, et al. The effects of intraarticular administration of hyaluronic acid on osteoarthritis of the knee: a clinical study with immunological and biochemical evaluations. Eur J Rheumatol Inflamm 1995; 15: 47-56.

[31] Carrabba MP, Paresce E, Angelini M, Re KA, Torchiana EEM, Perbellini A. The safety and efficacy of different dose schedules of hyaluronic acid in the treatment of painful osteoarthritis of the knee with joint effusion. Eur J Rheumatol Inflamm 1995; 15: 25-31.

[32] Altman RD, Moskowitz R. Intraarticular sodium hyaluronate (Hyalgan) in the treatment of patients with osteoarthritis of the knee: a randomized clinical trial. Hyalgan Study Group. J Rheumatol 1998; 25: 2203-12.

[33] Huskisson EC, Donnelly S. Hyaluronic acid in the treatment of osteoarthritis of the knee. Rheumatology (Oxford) 1999; 38: 602-7.

[34] Bunyaratavej N, Chan KM, Subramaniam N. Treatment of painful osteoarthritis of the knee with hyaluronic acid results of a multicenter Asian study. J Med Assoc Thai 2001; 84: S576-81.

[35] Jubb RW, Piva S, Beinat L, Dacre J, Gishen P. A one-year, randomised, placebo (saline) controlled clinical trial of 500-730 $\mathrm{kDa}$ sodium hyaluronate (Hyalgan) on the radiological change in osteoarthritis of the knee. Int J Clin Pract 2003; 57: 467-74.

[36] DeCaria JE, Montero-Odasso M, Wolfe D, Chesworth BM, Petrella RJ. The effect of intra-articular hyaluronic acid treatment on gait velocity in older knee osteoarthritis patients: a randomized, controlled study. Arch Gerontol Geriatr 2012; 55: 310-5.

[37] Huang TL, Chang CC, Lee CH, Chen SC, Lai CH, Tsai CL. Intraarticular injections of sodium hyaluronate $(\operatorname{Hyalgan}(\mathrm{R}))$ in osteoarthritis of the knee. a randomized, controlled, double-blind, multicenter trial in the Asian population. BMC Musculoskelet Disord 2011; 12: 221.

[38] Bragantini A, Cassini M, De Bastiani G, Perbellini A. Controlled single-blind trial of intra-articularly injected hyaluronic acid (Hyalgan ${ }^{\circledR}$ ) in osteo-arthritis of the knee. Clin Trials J 1987; 24: 333-40.

[39] Puhl W, Bernau A, Greiling $\mathrm{H}$, et al. Intra-articular sodium hyaluronate in osteoarthritis of the knee: a multicenter, doubleblind study. Osteoarthr Cartil 1993; 1: 233-41.

[40] Lohmander LS, Dalen N, Englund G, et al. Intra-articular hyaluronan injections in the treatment of osteoarthritis of the knee: a randomised, double blind, placebo controlled multicentre trial. Hyaluronan Multicentre Trial Group. Ann Rheum Dis 1996; 55: 424-31.

[41] Day R, Brooks P, Conaghan PG, Petersen M. A double blind, randomized, multicenter, parallel group study of the effectiveness and tolerance of intraarticular hyaluronan in osteoarthritis of the knee. J Rheumatol 2004; 31: 775-82.

[42] Brandt KD, Block JA, Michalski JP, Moreland LW, Caldwell JR, Lavin PT. Efficacy and safety of intraarticular sodium hyaluronate in knee osteoarthritis. ORTHOVISC Study Group. Clin Orthop Relat Res 2001; 385: 130-43.

[43] Sezgin M, Demirel AC, Karaca C, et al. Does hyaluronan affect inflammatory cytokines in knee osteoarthritis? Rheumatol Int 2005; 25: 264-9.

[44] Kul-Panza E, Berker N. Is hyaluronate sodium effective in the management of knee osteoarthritis? A placebo-controlled doubleblind study. Minerva Med 2010; 101: 63-72.

[45] Altman RD, Rosen JE, Bloch DA, Hatoum HT, Korner P. A double-blind, randomized, saline-controlled study of the efficacy and safety of EUFLEXXA for treatment of painful osteoarthritis of the knee, with an open-label safety extension (the FLEXX trial). Semin Arthritis Rheum 2009; 39: 1-9.

[46] Blanco FJ, Fernandez-Sueiro JL, Pinto-Tasende JC. Intra-articular hyaluronan treatment of patients with knee osteoarthritis waiting for replacement surgery. Open Arthritis J 2008; 1: 1-7.

[47] Navarro-Sarabia F, Coronel P, Collantes E, et al. A 40-month multicentre, randomised placebo-controlled study to assess the efficacy and carry-over effect of repeated intra-articular injections 
of hyaluronic acid in knee osteoarthritis: the AMELIA project. Ann Rheum Dis 2011; 70: 1957-62.

[48] Petrella RJ, DiSilvestro MD, Hildebrand C. Effects of hyaluronate sodium on pain and physical functioning in osteoarthritis of the knee: a randomized, double-blind, placebo-controlled clinical trial. Arch Intern Med 2002; 162: 292-8.

[49] Strand V, Baraf HS, Lavin PT, Lim S, Hosokawa H. A multicenter, randomized controlled trial comparing a single intra-articular injection of Gel-200, a new cross-linked formulation of hyaluronic acid, to phosphate buffered saline for treatment of osteoarthritis of the knee. Osteoarthr Cartil 2012; 20: 350-6.

[50] Petrella RJ, Petrella M. A prospective, randomized, double-blind, placebo controlled study to evaluate the efficacy of intraarticular hyaluronic acid for osteoarthritis of the knee. J Rheumatol 2006; 33: 951-6.

[51] Petrella RJ, Decaria J, Petrella M. Long term efficacy and safety of a combined low and high molecular weight hyaluronic acid in the treatment of osteoarthritis of the knee. Rheumatol Rep 2011; 3: 1620

(C) Pal et al.; Licensee Bentham Open.

This is an open access article licensed under the terms of the Creative Commons Attribution Non-Commercial License (http://creativecommons.org/licenses/by-nc/ 3.0/) which permits unrestricted, non-commercial use, distribution and reproduction in any medium, provided the work is properly cited. 